DOI 10.37882/2223-2982.2021.05.22

\title{
ПРИМЕНЕНИЕ РОУП-СКИППИНГА КАК СРЕДСТВА РАЗВИТИЯ СКОРОСТНО-СИЛОВЫХ КАЧЕСТВ У ДЕТЕЙ 10-12 ЛЕТ В СИСТЕМЕ ДОПОЛНИТЕЛЬНОГО ФИЗИЧЕСКОГО ОБРАЗОВАНИЯ
}

\section{USE OF ROPE SKIPPING AS A MEANS OF DEVELOPING HIGH-SPEED POWER QUALITIES IN CHILDREN 10-12 YEARS OLD IN THE SYSTEM OF ADDITIONAL PHYSICAL EDUCATION}

\section{E. Lebedeva \\ I. Koroleva \\ A. Mitrofanova \\ I. Sokolova}

Summary: The most priority area in the field of additional education is the development and strengthening of the health of the younger generation. Due to the predominance of sedentary lifestyle, the development of physical qualities in school-age children is becoming especially relevant today. At the same time, in order for development to be as effective as possible, it is necessary that classes be held in a form interesting to children. One such means of developing physical qualities in school-age children is rope skipping.

Keywords: skipping, a skipping rope, physical development, additional education, jumping.
Лебедева Евгения Геннадьевна

Доцент, Вологодский государственный университет jenya1433@yandex.ru

Королева Ирина Валентиновна

Старший преподаватель, Вологодский государственный университет

Митрофанова Анастасия Геннадьевна Старший преподаватель, Вологодский государственный университет

Соколова Ирина Юрьевна Старший преподаватель, Вологодский государственный университет

Аннотация: Наиболее приоритетным направлением в сфере дополнительного образования является развитие и укрепление здоровья подрастающего поколения. В связи с преобладанием сидячего образа жизни, развитие физических качеств у детей школьного возраста приобретает сегодня особенную актуальность. При этом, для того, чтобы развитие происходило максимально эффективно, необходимо, чтобы занятия проводились в интересной для детей форме. Одним из таких средств развития физических качеств у детей школьного возраста является роуп-скиппинг.

Ключевые слова: скиппинг, скакалка, физическое развитие, дополнительное образование, прыжки.
$\mathrm{O}$ дной из важнейших задач, поставленных перед современной системой образования, является необходимость сохранения и укрепления здоровья нации средствами физической культуры и спорта.

В настоящее время физическому воспитанию отводится значительная роль в воспитательно-образовательном процессе. Все больше акцентируется внимания на деятельности тренеров и учителей физической культуры не только в основной своей педагогической работе, но и в сфере дополнительного физического образования. На сегодняшний день требования к тренерской работе таковы, что появляется очевидная необходимость перехода на качественно новый и более эффективный уровень организации образовательного процесса, так как использование стандартного подхода уже не приносит желаемого результата. Теория и практика спортивной деятельности постоянно требует использования инновационных подходов к работе.

Одним из таких средств развитие физических ка- честв у детей, применяемым относительно недавно в дополнительном физическом образовании, является «роуп-скиппинг». Данный вид спорта был изобретен в 1985 году учителем физкультуры Ричардом Стендали в целях отвлечения детей от пагубного влияния улицы. Роуп-скиппинг имеет 4 основных направления: одиночная короткая скакалка, китайское колесо, путешественник и дабл датч, а также 11 дисциплин в командном зачете и 4 дисциплины в личном зачете (по версии Международной федерации роуп-скиппинга) [2]. Роуп-скиппинг постоянно и динамично развивается, благодаря чему возрастает эффективность тренировочного процесса, а также достигаются высокие результаты на соревнованиях.

Сегодня этот вид спорта используется для развития у детей физических качеств, а также удовлетворения потребности в двигательной активности, так как в повседневной жизни детей преобладает сидячий образ жизни [5]. Анализ проведенных исследований о применении средств роуп-скиппинга в физической подготовке детей 
и подростков позволяет сделать выводы о практически полном отсутствии подобных систем применения физических упражнений на уроках физической культуры в школе. Отмечаются лишь эпизодические упражнения со скакалкой, применяемые для развития скоростно-силовых качеств в секционных формах занятий в некоторых видах спорта, однако целостной методики применения скиппинга в системе дополнительного образования, направленной на развитие физических качеств и повышение физической подготовленности, не разработано [3].

Цель исследования - экспериментально проверить влияние применения средств роуп-скиппинга на развитие скоростно-силовых качеств у детей 10-12 лет в системе дополнительного физического образования. Исследование проводилось в течение шести месяцев на базе цирковой студии «FRAPPE». Прыжки давались в начале каждой тренировки экспериментальной группе детей, у контрольной группы занятия проводились в обычном режиме без применения технологии роуп-скиппинга, занятия проводились 3 раза в неделю.

Следуя рекомендациям В.В. Бойко, в структуре организованных занятий с применением технологии роупскиппинга выделялась следующая структура занятий: разминка, аэробная часть, кардиореспираторный элемент тренировки, силовая часть, стретчинг (развитие гибкости), восстановительная часть. Данная обобщенная структура тренировки скиппинга может видоизменяться в зависимости от уровня физической подготовки обучающихся и целевого направления программы тренировки.

В начале тренировок занимающимся было рекомендовано начинать прыжки в спокойном темпе, постепенно его увеличивая, так как нами учитывалась высокая степень влияния прыжковых упражнений на дыхательную и сердечно-сосудистую системы. Таким образом, нагрузка увеличивалась, исходя из подготовленности каждого ребенка индивидуально, начиная с одной минуты до 5-6 минут. Интенсивные прыжки в течение 2-3 минут чередовались с минутными перерывами для восстановления дыхания и отдыха [1].

На занятиях использовались четыре вида прыжков, направленных на развитие скоростно-силовых качеств:

1. Прыжки классические вперед. По команде «Старт!» спортсмен начинает вращать скакалку сзади вверх, вперед, вниз. Внизу скакалка продолжает движение назад, и, когда она оказывается в крайнем нижнем положении, спортсмен перепрыгивает через нее. Скакалка оказывается сзади, что засчитывается за один прыжок. Далее спортсмен продолжает совершать прыжки до команды «Стоп!».
2. Прыжки классические назад. По команде «Старт!» спортсмен начинает вращать скакалку спереди вверх, назад, вниз. Внизу скакалка продолжает движение вперед, и, когда она оказывается в крайнем нижнем положении, спортсмен перепрыгивает через нее. Скакалка оказывается спереди, что засчитывается за один прыжок. Далее спортсмен продолжает совершать прыжки до команды «Стоп!».

3. Прыжки с попеременной сменой ног, вращение скакалки вперед. По команде «Старт!» спортсмен начинает вращать скакалку сзади вверх, вперед, вниз. Для правильной техники выполнения следует поднимать колени в прыжке высоко перед собой, примерно на 90 градусов. Таким образом, бедро в верхней точке будет параллельно полу. Чередовать подъемы по одной ноге, проворачивая кисти в таком темпе, чтобы скакалка не цеплялась за стопы. Далее спортсмен продолжает совершать прыжки до команды «Стоп!».

4. Прыжки на двух ногах, с двойным вращением скакалки вперёд. По команде «Старт!» спортсмен начинает вращать скакалку спереди вверх, назад, вниз. При двойном прыжке скакалка проходит под ногами два раза за один прыжок. Для того чтобы успешно выполнить двойной прыжок, потребуется вращать скакалку быстро и прыгать выше, чем обычно, чтобы позволить скакалке пройти дважды, прежде чем приземлиться. Далее спортсмен продолжает совершать прыжки до команды «Стоп!».

По истечении педагогического эксперимента стали заметны положительные изменения скоростно-силовых качеств в экспериментальной группе детей. Показатели результатов в прыжках в длину с места имели положительную динамику у девочек на 7,5\%, у мальчиков на $12,1 \%$. В челночном беге результаты улучшились у девочек на $8,3 \%$, у мальчиков на $11,6 \%$. Степень увеличения результатов в беге на 30 м у мальчиков составила 15,6\%, у девочек $9,8 \%$. По всем видам тестов, проведенных на начальном и конечном этапе исследования прослеживается положительная динамика. Таким образом, проанализировав результаты проведенных тестов, характеризующих изменения скоростно-силовых качеств, нами было установлено, что применение скиппинга положительно способствует развитию скоростно-силовых способностей [4]. Также был проведен сравнительный анализ общей физической подготовленности контрольной и экспериментальной групп обучающихся, что позволяет сделать выводы об эффективности применения методики и средств роуп-скиппинга во время тренировок в дополнительном физическом образовании.

В результате проведения комплексного анализа экспертных оценок проведенных тестов можно констати- 
ровать, что обучающиеся из экспериментальной группы выполняют прыжки и упражнения на скакалке более качественно по сравнению с контрольной группой. На конечном этапе исследования у экспериментальной группы достоверно зафиксирована значительная разница значений экспертных значений по всем видам прыжков.
В процессе проведенного исследования было установлено, что специально разработанные методики и комплексы прыжковых упражнений со скакалкой позволяют добиться значительных улучшений скоростносиловых способностей и с успехом могут применяться в дополнительном физическом образовании.

\section{ЛИТЕРАТУРА}

1. Антуфьев Д.А. С использованием скакалки, веревки и каната / Д.А. Антуфьев. - Физическая культура в школе. - 2017. №2 С. 16-21.

2. Бойко В.В. Прыжки через скакалку при реабилитации спортстменов / В.В. Бойко. - Наука-2020. 2016. №5. С. 12-14.

3. Валеев Э. Прыжковый марафон упражнений со скакалкой / Спорт в школе. - 2014. - №3. С. 20-21.

4. Колобова Л.В. Развитие координационных способностей у младших школьников в процессе обучения жонглированию мячами / Л.В. Колобова, М.А. Правдов, Д.М. Правдов. - Научный поиск. 2013. № 2.5. С. 62-64.

5. Миронов И.С. Динамические и пространственные характеристики точности движений / И.С. Миронов, М.А. Правдов, Д.М. Правдов. - Ученые записки университета им. П.Ф. Лесгафта. - 2015. №3 (121). С. 68-73.

6. Правдов М.А. Влияние занятий скиппингом на физическую подготовленность студентов / М.А. Правдов, М.А. Корнева. - Ученые записки университета П.Ф. Лесгафта. - 2010. № 7 (65). С.64-67.

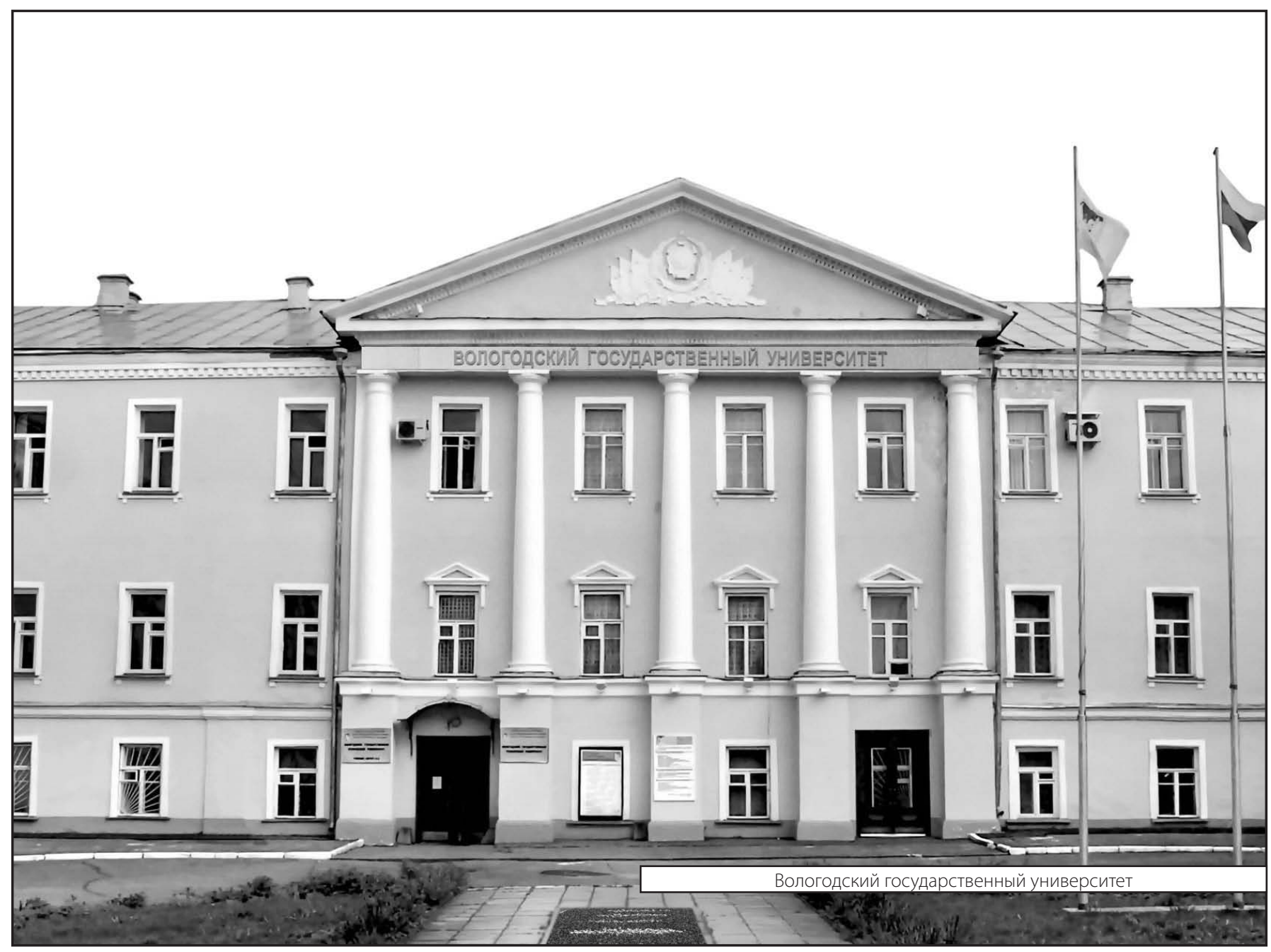

